\title{
Nonsense Mutation
}

National Cancer Institute ( $\mathrm{NCl})$

\section{Source}

National Cancer Institute (NCI). Nonsense mutation.

A genetic alteration that causes the premature termination of a protein. The altered protein may be partially or completely inactivated, resulting in a change or loss of protein function. Also called nonsense variant. 